\title{
Ant mosaics in Bornean primary rain forest high canopy depend on spatial scale, time of day, and sampling method
}

\author{
Kalsum M Yusah ${ }^{\text {Corresp., }}$ 1 , William A Foster ${ }^{2}$, Glen Reynolds ${ }^{3}$, Tom M Fayle ${ }^{4,5}$ \\ 1 Institute for Tropical Biology and Conservation, Universiti Malaysia Sabah, Kota Kinabalu, Sabah, Malaysia \\ 2 Department of Zoology, University of Cambridge, Cambridge, Cambridgeshire, United Kingdom \\ 3 The SE Asia Rainforest Research Partnership (SEARRP), Lahad Datu, Sabah, Malaysia \\ 4 Institute of Entomology, Biology Centre, Czech Academy of Sciences, Ceske Budejovice, South Bohemia, Czech Republic \\ 5 Faculty of Science, University of South Bohemia, Ceske Budejovice, South Bohemia, Czech Republic \\ Corresponding Author: Kalsum M Yusah \\ Email address: kalsum.myusah@gmail.com
}

Background: Competitive interactions in biological communities can be thought of as giving rise to "assembly rules" that dictate the species that are able to co-exist. Ant communities in tropical canopies often display a particular pattern, an "ant mosaic", in which competition between dominant ant species results in a patchwork of mutually exclusive territories. Although ant mosaics have been well-documented in plantation landscapes, their presence in pristine tropical forests remained contentious until recently. Here we assess presence of ant mosaics in a hitherto under-investigated forest stratum, the emergent trees of the high canopy in primary tropical rain forest, and explore how the strength of any ant mosaics is affected by spatial scale, time of day, and sampling method. Methods: To test whether these factors might impact the detection of ant mosaics in pristine habitats, we sampled ant communities from emergent trees, which rise above the highest canopy layers in lowland dipterocarp rain forests in North Borneo (38.8 - 60.2 m), using both baiting and insecticide fogging. Critically, we restricted sampling to only the canopy of each focal tree. For baiting, we carried out sampling during both the day and the night. We used null models of species co-occurrence to assess patterns of segregation at within-tree and between-tree scales. Results: The numerically dominant ant species on the emergent trees sampled formed a diverse community, with differences in the identity of numerically dominant species between times of day and sampling methods. Between trees, we found patterns of ant species segregation consistent with the existence of ant mosaics using both methods. Within trees, fogged ants were segregated, while baited ants were segregated only at night. Discussion: We conclude that ant mosaics are present within the emergent trees of the high canopy of tropical rain forest in Malaysian Borneo, and that sampling technique, spatial scale, and time of day interact to determine observed patterns of segregation. Restricting sampling to only emergent trees reveals segregatory 
patterns not observed in ground-based studies, confirming previous observations of stronger segregation with increasing height in the canopy. 
1 Ant mosaics in Bornean primary rain forest high canopy depend on

2 spatial scale, time of day, and sampling method

$4{ }^{1}$ Institute for Tropical Biology and Conservation, Universiti Malaysia Sabah, Kota Kinabalu, Sabah, 5 Malaysia.

$6 \quad{ }^{2}$ Insect Ecology Group, University Museum of Zoology Cambridge, Cambridge, UK

$7 \quad{ }^{3}$ The SE Asia Rainforest Research Partnership (SEARRP), Danum Valley Field Centre, Lahad Datu,

8 Sabah, Malaysia

$9 \quad{ }^{4}$ Biology Centre, Czech Academy of Sciences, Institute of Entomology, Ceske Budejovice, Czech

10 Republic

$11{ }^{5}$ Faculty of Science, University of South Bohemia, Ceske Budejovice, Czech Republic

12 Corresponding author:

13 Kalsum Mohd Yusah

14 Institute for Tropical Biology and Conservation, Universiti Malaysia Sabah, Jalan UMS, 88400 Kota

15 Kinabalu, Sabah, Malaysia. Corresponding author: kalsum.myusah@gmail.com

16 Short title: Ant mosaics in Borneo rain forest high canopy 


\section{Abstract}

18 Background: Competitive interactions in biological communities can be thought of as giving rise to "assembly rules" that dictate the species that are able to co-exist. Ant communities in tropical canopies often display a particular pattern, an "ant mosaic", in which competition between dominant ant species results in a patchwork of mutually exclusive territories. Although ant mosaics have been well-documented in plantation landscapes, their presence in pristine tropical forests remained contentious until recently. Here we assess presence of ant mosaics in a hitherto under-investigated forest stratum, the emergent trees of the high canopy in primary tropical rain forest, and explore how the strength of any ant mosaics is affected by spatial scale, time of day, and sampling method.

Methods: To test whether these factors might impact the detection of ant mosaics in pristine habitats, we sampled ant communities from emergent trees, which rise above the highest canopy layers in lowland dipterocarp rain forests in North Borneo (38.8 - 60.2 m), using both baiting and insecticide fogging.

Critically, we restricted sampling to only the canopy of each focal tree. For baiting, we carried out sampling during both the day and the night. We used null models of species co-occurrence to assess patterns of segregation at within-tree and between-tree scales.

Results: The numerically dominant ant species on the emergent trees sampled formed a diverse community, with differences in the identity of numerically dominant species between times of day and sampling methods. Between trees, we found patterns of ant species segregation consistent with the existence of ant mosaics using both methods. Within trees, fogged ants were segregated, while baited ants were segregated only at night.

Discussion: We conclude that ant mosaics are present within the emergent trees of the high canopy of tropical rain forest in Malaysian Borneo, and that sampling technique, spatial scale, and time of day interact to determine observed patterns of segregation. Restricting sampling to only emergent trees reveals segregatory patterns not observed in ground-based studies, confirming previous observations of

41 stronger segregation with increasing height in the canopy.

43 Species' colonisation of natural habitats can be influenced by various factors, including interactions with 
44 other species and variation in the physical environment. Understanding the assembly rules that describe

45 these processes is a fundamental objective of ecology (Gotelli \& McCabe 2002). Inter-specific competition, a process that is well known to influence species assembly, should be greatest between species that have similar niches, for example in terms of their morphology, function and pattern of resource use. This produces distinctive patterns of species co-occurrence (Gotelli \& Ellison 2002). Species that share the same resource should co-occur less often than expected by chance, and conversely, where species do co-occur, they should differ substantially in resource use (Gotelli \& Ellison 2002).

Competition between species is thought to be a strong force structuring ant communities (Hölldobler \& Wilson 1990), although recently this view has been challenged (Cerdá et al. 2013; Gibb \& Johansson 2011). Competition between ant colonies involves territory defence (Adams 1994; Tanner \& Adler 2009), nest site selection and protection (Dejean et al. 2008; Fayle et al. 2015), and competition for food resources (Blüthgen et al. 2004; Blüthgen \& Fiedler 2004; Blüthgen et al. 2006). In tropical canopy ant communities, competition sometimes results in the formation of patterns known as "ant mosaics". Ant mosaics are defined as occurring where there is a hierarchical structure, dominated by a particular set of species, which may tolerate the presence of a small number of subordinate species (generally those with less populous colonies and low levels of aggressiveness) in their territories (Blüthgen \& Stork 2007; Dejean et al. 2007). The identity of these subordinate species is sometimes determined by the identity of the dominant species present (Room 1971). The dominant ant species do not tolerate each other's presence, and react aggressively to any dominant ant individual that is not from their colony (either conspecific or heterospecific). Thus large colonies of dominant ants with defended territories can shape the pattern of ant distribution in the canopy, such that the presence of other ant colonies is not random (Dejean \& Corbara 2003). If these territories extend across multiple tree canopies, then the result is a "mosaic" of mutually exclusive dominant species. The formation of ant mosaics has implications for the broader ecology of forest canopies, since the identity of the dominant ant species can have impacts on other taxa, including those of functional importance (Dejean et al. 1997).

Ant mosaics have been studied in many habitat types (e.g. Blüthgen \& Stork 2007; Majer \& Camer-Pesci 1991) and are often described as characteristic elements of canopy ant communities from tropical agricultural systems (Majer et al. 1994; Pfeiffer et al. 2008; Room 1971; Room 1975) and from disturbed 
73 secondary forests (Dejean et al. 2016; Dejean \& Corbara 2003). However, until recently, their presence in

74 the canopies of undisturbed tropical forests remained contentious. Direct observations at ground level of

75 canopy species that descend to forage in this stratum shows strong segregation between dominant

76 species (Davidson et al. 2007). Sampling the lower canopy of tropical forests using insecticide fogging

77 does not detect any mosaic-like pattern (Floren \& Linsenmair 2000), while ground-based fogging targeting

78 the canopy as a whole, the results of which are also likely influenced by lower canopy layers, also fails to detect any mosaic pattern (Fayle et al. 2013). However, canopy sampling conducted in situ, using a canopy crane (Ribeiro et al. 2013) and a range of other direct canopy access methods (Dejean et al. 2000; Dejean et al. 2015), reveals the presence of strong mosaic patterns.

Despite this progress in terms of understanding the structure of ant mosaics in the upper canopy layers in tropical rainforest, there remain outstanding questions. It is not yet known how detection of ant mosaics is affected by the sampling method used, spatial scale of sampling, or time of day at which sampling took place. For example, studies using baiting tend to find species segregation (e.g. Ribeiro et al. 2013), while those using fogging give more variable results, at least in primary forests, with some studies finding segregation (Blüthgen \& Stork 2007), and some showing random co-occurrence between species (Fayle et al. 2013; Floren \& Linsenmair 2005). Furthermore, ground-based fogging might not test adequately for ant mosaics in the high canopy, since this method is likely to sample a range of unconnected canopy strata, predominantly the lower layers, relating to different trees (Blüthgen \& Stork 2007; Dial et al. 2006), and leading to apparently random co-occurrence simply because many species found in a single sample would not be sufficiently connected to each other to interact. Furthermore, although ant mosaics are usually characterised by mutual exclusion of dominant species at the scale of entire individual trees, the impact of (horizontal) spatial scale of sampling on patterns of segregation is not known, in particular, whether patterns of segregation at smaller scales, within trees, differ from those between trees. Finally, although the manner in which canopy ant activity changes with time of day has been documented (e.g. Tanaka et al. 2010), the impact of these changes on patterns of species segregation are not known.

We tested whether using different sampling methods, restricting sampling to the uppermost canopy layer, sampling at different spatial scales (with replication both within trees and between trees), and sampling at different times of day affects patterns of species segregation. We sampled canopy ants in the same forest 
trays into the canopies of emergent trees (following Ellwood \& Foster 2004), hence ensuring that only the focal tree was sampled. Note that because individual emergent trees are usually not directly adjacent to each other, this situation differs from a number of other ant mosaic studies, where continuous areas of canopy were surveyed. The same trees were also sampled using a bait-based method during both the day and the night. We used null modelling of species co-occurrence to test for differences in patterns of species segregation at both within- and between-tree scales. Descriptions of ant community composition are presented elsewhere (Yusah et al. 2012; Yusah \& Foster 2016).

\section{Materials and methods}

\section{Field sampling}

We collected ants from 20 emergent trees (range 38.8 - $60.2 \mathrm{~m}$ height) of the genus Parashorea in lowland dipterocarp rain forest in Danum Valley Conservation Area (DVCA), Sabah, Malaysian Borneo $\left(117^{\circ} 49^{\prime} \mathrm{E}, 5^{\circ} 01^{\prime} \mathrm{N}\right.$, elevation $\left.170 \mathrm{~m}\right)$ during the periods 13 September 2007-29 February 2008 and 28 March-20 August 2008. Trees belonged to the species P. tomentella $(\mathrm{N}=5)$ and $P$. malaanonan $(\mathrm{N}=15)$, between which there were no differences in ant species composition (Yusah \& Foster 2016). KMY received permission to conduct fieldwork in DVCA from Danum Valley Management Committee. These trees are part of the high canopy, but emerge above the continuous canopy layer, with which they are only poorly connected. We chose to test for the presence of ant mosaics across widely spaced sampling points, rather than by sampling a smaller, continuous area. While we were unable to document the spatial extent of individual ant territories, we were nonetheless able to test for patterns of segregation between ant species that would support the existence of an ant mosaic (note that ant mosaics are defined as being mutually exclusive dominance of particular ant species across multiple adjacent canopies). Furthermore, because our sampling points were widely spaced, our results are more likely to be representative of patterns at broader spatial scales than if we had sampled a smaller, continuous area.

Two methods were used: 1 . Purse-string trapping ( $\mathrm{N}=8$ traps per tree), which allows remote collection of baited traps without disturbance of the baits prior to collection (Figure $1 \mathrm{~A}$; Yusah et al. 2012) and 2.

Canopy fogging ( $\mathrm{N}=201 \mathrm{~m}^{2}$ trays per tree) in which both trays and fogging machine were hoisted into the canopy (Figure $1 \mathrm{~B}$ ). Both of these methods allow collection of ants from a single canopy, minimising unwanted sampling of ants from other trees, which is vital if ant communities are to be assessed for 
130 interactions. The two sampling methods are complementary, in that baiting samples the ants that

131 dominate food resources, while fogging samples more broadly the species with foraging workers present

132 in the canopy. Canopy work was conducted using rope access methods (Figure $1 \mathrm{C}$ ). Baiting was carried

133 out both during the day and the night ( $\mathrm{N}=8$ per time of day), near and far from the main trunk ( $\mathrm{N}=4$ per

134 distance) and using two different bait types: tuna and sugar water ( $\mathrm{N}=4$ per tree). Baiting was always

135 carried out before fogging. Analysis of community composition showed that baiting communities differed

136 between the day and night (CCA on square root transformed abundances, permutation test: $F=4.13$,

$137 \mathrm{P}=0.001$, no. of permutations=999), but not between bait types $(F=1.21, P=0.184$, $n$ perm=999), or

138 distances from the trunk $(F=1.35, P=0.090, n$ perm=999). Hence, separate co-occurrence analyses were

139 carried out for day and night samples (see below).

Ant identification

Ants were identified to genus (Bolton 1994; Hashimoto 2007), and then sorted to morphospecies, with species names assigned where possible (Bolton 1974; Brown 1978; Fisher 2010; Pfeiffer 2013; Rigato 1994; Schödl 1998).

\section{Statistical analysis}

We used null model analyses to examine whether the ant assemblages occurring in the 20 sampled trees were structured at random or in a deterministic pattern that would be consistent with the existence of an ant mosaic. Analyses were carried out at two different spatial scales to examine whether co-occurrence patterns were scale-dependent: firstly within each tree (although with results summed across all trees) and secondly between all trees, the scale that corresponds to the traditional notion of an ant mosaic. Analyses were conducted in R 2.9.2 (http://www.R-project.org; see Supplemental Appendix S1 for code, Appendix S2 for data), utilising the vegan package (Oksanen et al. 2011). Three matrices were created comprising the ants trapped during the day and night ( $\mathrm{N}=160$ traps each across 20 trees, two matrices), and those caught using fogging ( $\mathrm{N}=400$ traps across 20 trees, one matrix).

We first tested for significant segregation within each tree by running within-tree analyses for all 20 trees and combining the results. This was carried out by counting the number of checkerboard units in the submatrix comprising the samples from each tree. Checkerboard units $(\mathrm{CU})$ are counted by looking across all 
157 possible pairs of species and pairs of sampling locations (i.e. between fogging trays or purse-string traps

158 in the case of this study). A checkerboard unit occurs when, comparing the occurrence of two species

159 across two sampling locations, only one species occurs in each area, with each area containing a different

160 species (Stone \& Roberts 1990). We summed the number of checkerboards obtained from each tree

161 across 20 trees to give an observed within-tree chequerboard count. To obtain the distribution of

162 checkerboard units expected if species co-occurred at random within trees, the matrix from each tree was

163 randomised while keeping the number of species per site and the number of occurrences per species

164 constant. This was done using the quasiswap algorithm of the commsimulator function in R. Critically,

165 randomisation was only conducted within each tree. All checkerboard units for the simulated data were

166 then summed across all 20 randomised trees (in the same way as for the observed data) and this process

167 was repeated 1000 times. The observed number of checkerboard units was then compared to this null

168 distribution to give the probability of obtaining that many checkerboard units or more under the null

169 hypothesis of species co-occurring at random to each other i.e. to generate a P-value. Note that we did

170 not standardise the number of chequerboard units by matrix size to give a C-score (Gotelli 2000), because

171 we wished to sum the total number of units across all matrices.

172 We then examined the pattern of assemblages across larger scales, between trees, to determine whether

173 or not species co-occurrence between trees differed from random. Twenty "virtual trees" were made by

174 picking eight traps or 20 fogging trays (from eight or 20 trees respectively) while ensuring that there were

175 never two or more traps from the same tree. Analysis of the 20 virtual trees was then carried out as above.

176 The process was repeated 10 times to reduce variations caused by random sampling in the construction

177 of virtual trees. The resulting ten P-values were averaged. Since we ensured that the analyses looking at

178 within-tree and between-tree scales used exactly the same sample size and data structure, results from

179 the first analysis and the second analysis were directly comparable, because the tests should have the

180 same statistical power. This would not have been the case if data from all traps of one kind within a tree

181 were combined, and analyses carried out using these much larger samples. Note that just one of these

182 ten replicated histograms is plotted for each analysis of between-tree patterns of segregation.

\section{Results}


184 We found diverse ant communities in the Parashorea canopies (Figure 2). For fogging (only conducted

185 during the day), the numerically dominant ant species were Vollenhovia sp. 5 (most abundant species on

1864 trees), Dolichoderus thoracicus (3 trees), Myrmicaria sp. 1 (2 trees), and Crematogaster difformis (2

187 trees). Nine other different species numerically dominated the remaining nine trees. Baiting during the day

188 gave a completely different result in terms of numerical dominance, with a different species Vollenhovia

189 sp. 2 most abundant on seven trees. Other numerically dominant species included Tetramorium laparum

190 (2 trees) and Dolichoderus magnipastor (2 trees) with the remaining nine trees being dominated by

191 different species. Polyrhachis ypsilon was present on six trees, but only numerically dominant on a single

192 tree, although simple numerical dominance probably underestimates the impact of this large-bodied

193 species. Overall, the numerically dominant species differed between fogging and baiting for 17 of the 20

194 trees, with only three trees being consistent between sampling methods (inhabited by Crematogaster

195 difformis, Vollenhovia 2, and D. magnipastor).

196 For baiting at night, Vollenhovia sp. 2 (the same species that was dominant during the day) was most

197 abundant on four trees, Dinomyrmex gigas on three trees, and Camponotus sp. 2 on two trees.

198 Dinomyrmex gigas was present at lower abundances (but presumably still high biomass, since they have

199 large body size) on a number of other trees (14 in total). The most numerically dominant species differed

200 between the day and the night for 12 of the 20 trees. Specifically, Vollenhovia sp. 2, Dolichoderus

201 magnipastor, Tetramorium laparum, were dominant on trees during the day and also remained so at night,

202 while in other trees, new species became more abundant at night, the most abundant of which was

203 Dinomyrmex gigas. Tetramorium laparum, although persisting on most trees at night, was replaced by

204 Camponotus sp. 7 on one tree (tree 20).

205 We found species segregation, consistent with the existence of ant mosaics, at between-tree scales for

206 both fogging (Figure 3 B) and baiting (Figure 3 D, F). That is, there were pairs of species that co-occurred

207 on entire trees less often than would be expected by chance. At within-tree scales, baited ants collected

208 during the day were not segregated (Figure $3 \mathrm{C}$ ), that is, there were no patterns of exclusion between

209 species for sites within the same tree. However, within trees, fogged ants (Figure 3 A) and baited ants

210 collected during the night (Figure $3 \mathrm{E}$ ) were segregated. These patterns of segregation were present

211 despite the diverse nature of the ant community, with considerable turnover of species between trees, and 
212 high species richness within individual trees during both the day and the night (for baiting) and for different 213 sampling methods (Figure 2).

\section{Discussion}

215 High-canopy mosaics at between-tree scales were detectable using both fogging and baiting. This 216 confirms previous studies targeting sampling in the high canopy of primary forests that found strong 217 segregation between species (Dejean et al. 2015; Ribeiro et al. 2013). Although the rarity of species 218 precludes isolation of the particular species driving these patterns of segregation, we can speculate on possible dominants monopolising tree canopies. One candidate species for driving these patterns is Crematogaster difformis, a species inhabiting the myrmecophytic epiphytic ferns, Lecanopteris sp. and Platycerium sp., which has previously been demonstrated to reduce canopy ant species richness and abundance (Tanaka et al. 2010), and is even sufficiently dominant that it protects the fern's host tree from herbivory (Tanaka et al. 2009). A second possible behaviourally dominant species is Dolichoderus thoracicus, which is known to form mosaic patterns in plantations with Oecophylla smaragdina (Way \& Khoo 1991). A second species in this genus, Dolichoderus magnipastor, a Bornean endemic known to tend sap-sucking Allomyrmococcini bugs (Dill et al. 2002), is also likely to be a behaviourally dominant species driving these patterns (note that Dill et al. (2002) describe the species as diurnal, but we also collected them from baits during the night). The most abundant species for any one sampling method was Vollenhovia sp. 2, which was most abundant at seven trees at baits during the day. To our knowledge, Vollenhovia has not been found previously to be a dominant genus in the high canopy of rain forest, or any other habitat, although it has been found rarely in canopies in both plantation (Pfeiffer et al. 2008; Room 1975) and rain forest (Floren \& Linsenmair 2000). Finally, although present in low abundances, Dinomyrmex gigas has large body size, and was present on 14 of the 20 trees at night (baiting), and hence is another candidate as a dominant species in the upper canopy. Interestingly, Oecophylla smaragdina, a species know to be a highly dominant canopy species in primary forests elsewhere in Borneo (Davidson et al. 2007) was not found during sampling, and appears to be locally absent in the area surrounding Danum Valley Field Station, despite being present in nearby primary forests in Sabah (KMY, TMF pers. obs.). Overall, perhaps because sampling was spread between widely spaced trees, a diverse set of species contributed to the patterns of segregation observed through a kind of "diffuse competition". 
241 The robustness of patterns of segregation to the sampling methods employed is likely to be because

242 dominant ants are those that are both highly abundant in general, and are also those that dominate food

243 sources. The dominant species differed between the two sampling methods, hence demonstrating that the

244 ants that are generally numerically dominant in the canopy (fogging samples) and those that dominate

245 baits (baiting samples) both show patterns of segregation congruent with the existence of an ant mosaic.

246 The difference in community composition between the sampling methods also cautions against

247 comparison between studies using different methods; although the communities sampled using the two

248 methods showed similar patterns of segregation, this will not necessarily always be the case. Although

249 ants were segregated at larger scales regardless of the sampling method used, at smaller scales, within

250 the canopies of individual trees, fogging detected patterns of segregation, whereas baiting during the day

251 did not. This might relate to lower statistical power of baiting, due to the smaller number of species present

252 at each bait (mean $=1.9$ species per bait for day baiting), compared with each fogging tray $($ mean $=5.6$

253 species per tray). Alternatively, fogging and baiting might sample different aspects of within-tree ant spatial

254 structuring, which seems likely, since they sample different overall communities.

255 Blüthgen \& Stork (2007) suggested that rain forest canopies may be too complex for detection of mosaics

256 after two studies (Floren \& Linsenmair 2000; Floren \& Linsenmair 2005) failed to demonstrate this pattern

257 in the continuous canopy layer of the lower rainforest canopy using ground-based fogging of individual

258 trees. However, our study was carried out within emergent trees where the canopies are isolated and

259 hence are more similar to those in the plantations where ant mosaics have been observed previously

260 (Majer 1976a; Majer 1976b). Therefore, the arguments by Floren \& Linsenmair (2000) that the absence of

261 an ant mosaic in their study was due to the habitat complexity within the canopy of tropical rainforest may

262 still be consistent with our results. Our results also contrast with those of Fayle et al. (2013) from the same

263 forest, who did not detect species segregation using ground-based fogging. Sampling entire vertical

264 columns of forest, as ground-based fogging does, is likely to result in collection of ants from multiple,

265 unconnected canopy layers, and hence will not reveal patterns of segregation limited to a particular

266 canopy stratum (Dial et al. 2006). Furthermore there may be a vertical gradient in strength of segregation,

267 with segregation being strongest at the top of the canopy (Ribeiro et al. 2013). Finally, isolated emergent

268 trees may be more easily defended, while the well-connected lower canopy will allow greater movement

269 and hence potentially result in less segregation in this stratum (although note that Dinomyrmex gigas, 
which nests on the forest floor, is nonetheless able to access these tree crowns).

271 In terms of spatial effects, the only difference for within and between-tree scales was found for baited ants 272 during the day, where ants were segregated between trees, but not within them. This was not an effect of 273 differing statistical power between the analyses, since we controlled for this using our null models (see

274 Methods). Such a pattern indicates random co-existence between a single dominant and several 275 subordinate species within each canopy, but with different dominants occupying different canopies. The 276 detection of segregation using the same sampling method at night might relate to the presence of

277 Dinomyrmex gigas (see below). However, it is not clear why the same dependence on spatial scale is not present for fogging data, where previous work showed random co-occurrence at small and large scales for ground based fogging (Fayle et al. 2013), in contrast to the segregation at both scales observed in this study.

At within-tree scales, time of day affected patterns of segregation. Baited ants were not segregated during the day, but were at night. (Note that we do not know whether fogging at night would have resulted in the same pattern.) This difference may be driven partly by temperature. When temperatures are excessively high for ants in the canopy, the majority of ants will reduce foraging activity, including dominant ants (Parr 2008), hence possibly reducing the chance of formation of mutually exclusive territories at this time. One candidate species for driving this pattern is Dinomyrmex gigas, an extremely large-bodied ground nesting species that maintains extensive three dimensional territories, both at ground level, and in the rain forest canopy (Pfeiffer \& Linsenmair 2000; Pfeiffer \& Linsenmair 2001). The species tends sap-sucking hemipterans (Pfeiffer \& Linsenmair 2007), which are presumably clumped in their distributions, potentially leading to segregation of ant communities at small scales during the night, driven by presence of $D$. gigas. During the day $D$. gigas was not present, and within tree segregation did not occur. The presence of this large-bodied species explains the how differences in segregation between times of day might have come about despite similarities in degree of numerical dominance between times (there were 17 trees that during the day had more than $50 \%$ of the total ant abundance comprising one species, with 16 showing this pattern at night). These results indicate that patterns of segregation at small scales at food sources shift over the course of 24 hours, and also caution against comparing results from different studies using these two methods at smaller scales. 


\section{Conclusions}

299 Taken together, our findings indicate that ant mosaics are present in the emergent trees of the high 300 canopy of tropical rain forest in Malaysian Borneo, and that sampling targeted specifically on this forest stratum is crucial for revealing species segregation. Furthermore, spatial scale, time of day, and sampling method (the latter partly driven by vertical stratification of patterns), interact to affect detected patterns of segregation.

\section{Acknowledgements}

We are grateful to the Royal Society's South East Asia Rainforest Research Partnership for logistic

support, Yayasan Sabah for permission to conduct research, and Ed Turner for constructive comments on the manuscript. We thank Jonathan Majer and one anonymous reviewer for feedback that has greatly improved this article.

\section{References}

Adams ES. 1994. Territory defense by the ant Azteca trigona: maintenance of an arboreal ant mosaic. Oecologia 97:202-208.

Blüthgen N, E Stork N, and Fiedler K. 2004. Bottom-up control and co-occurrence in complex communities: honeydew and nectar determine a rainforest ant mosaic. Oikos 106:344-358.

Blüthgen N, and Fiedler K. 2004. Preferences for sugars and amino acids and their conditionality in a diverse nectar-feeding ant community. Journal of Animal Ecology 73:155-166.

Blüthgen N, Mezger D, and Linsenmair KE. 2006. Ant-hemipteran trophobioses in a Bornean rainforest diversity, specificity and monopolisation. Insectes Sociaux 53:194-203.

Blüthgen N, and Stork NE. 2007. Ant mosaics in a tropical rainforest in Australia and elsewhere: A critical review. Austral Ecology 32:93-104.

Bolton B. 1974. A revision of the Palaeotropical arboreal ant genus Cataulacus F. Smith (Hymenoptera: Formicidae). Bulletin of the British Museum (Natural History) Entomology 30:1-105.

Bolton B. 1994. Identification guide to the ant genera of the world. Cambridge, Massachusetts: Harvard University Press. 
Brown WL. 1978. Contributions towards a reclassification of the Formicidae. Part VI. Ponerinae, tribe Ponerini, subtribe Odontomachiti. Section B. Genus Anochetus and bibliography. Studia Entomologica 20:549-651.

Cerdá X, Arnan X, and Retana J. 2013. Is competition a significant hallmark of ant (Hymenoptera: Formicidae) ecology? Myrmecological News 18:131-147.

Davidson DW, Lessard J-P, Bernau CR, and Cook SC. 2007. The tropical ant mosaic in a primary Bornean rain forest. Biotropica 39:468-475.

Dejean A, Azémar F, Céréghino R, Leponce M, Compin A, Corbara B, Orivel J, and Compin A. 2016. The dynamics of ant mosaics in tropical rainforests characterized using the Self-Organizing Map algorithm. Insect Science 23:630-637.

Dejean A, and Corbara B. 2003. A review of mosaics of dominant ants in rainforests and plantations: Cambridge University Press, Cambridge.

Dejean A, Corbara B, Orivel J, and Leponce M. 2007. Rainforest canopy ants: the implications of territoriality and predatory behavior. Functional Ecosystems and Communities 1:105-120.

Dejean A, Djiéto-Lordon C, and Durand JL. 1997. Ant mosaic in oil palm plantations of the southwest province of Cameroon: Impact on leaf miner beetle (Coleoptera: Chrysomelidae). Journal of Economic Entomology 90:1092-1096.

Dejean A, Grangier J, Leroy C, Orivel J, and Gibernau M. 2008. Nest site selection and induced response in a dominant arboreal ant species. Naturwissenschaften 95:885-889.

Dejean A, McKey D, Gibernau M, and Belin M. 2000. The arboreal ant mosaic in a Cameroonian rainforest (Hymenoptera: Formicidae). Sociobiology 35:403-423.

Dejean A, Ryder S, Bolton B, Compin A, Leponce M, Azémar F, Céréghino R, Orivel J, and Corbara B. 2015. How territoriality and host-tree taxa determine the structure of ant mosaics. The Science of Nature 102:33.

Dial R, Ellwood MDF, Turner EC, and Foster WA. 2006. Arthropod abundance, canopy structure, and microclimate in a Bornean lowland tropical rain forest. Biotropica 38:643-652.

Dill M, Williams DJ, and Maschwitz U. 2002. Herdsmen Ants and their Mealybug Partners. Abhandlungen der Senckenbergischen Naturforschende Gesellschaft, Stuttgart.

Ellwood MDF, and Foster WA. 2004. Doubling the estimate of invertebrate biomass in a rainforest canopy? Nature 429:549-551. 
354 Fayle TM, Eggleton P, Manica A, Yusah KM, and Foster WA. 2015. Experimentally testing and assessing the predictive power of species assembly rules for tropical canopy ants. Ecology Letters 18:254262.

Fayle TM, Turner EC, and Foster WA. 2013. Ant mosaics occur in SE Asian oil palm plantation but not rain

Fisher BL. 2010. www.antweb.org (accessed 20 March 2010).

Floren A, and Linsenmair E. 2000. Do ant mosaics exist in pristine lowland rain forests? Oecologia 123:129-137.

Floren A, and Linsenmair KE. 2005. The importance of primary tropical rain forest for species diversity: an

Gibb H, and Johansson T. 2011. Field tests of interspecific competition in ant assemblages: revisiting the dominant red wood ants. Journal of Animal Ecology 80:548-557.

Gotelli NJ. 2000. Null model analysis of species co-occurrence patterns. Ecology 81:2606-2621.

Gotelli NJ, and Ellison AM. 2002. Assembly rules for New England ant assemblages. Oikos 99:591-599.

Gotelli NJ, and McCabe DJ. 2002. Species co-occurrence: a meta-analysis of J. M. Diamond's assembly rules model. Ecology 83:2091-2096.

Hashimoto Y. 2007. Identification guide to ant genera of Borneo

Hölldobler B, and Wilson EO. 1990. The Ants: Cambridge: Belknap Press.

Majer J. 1976a. The ant mosaic in Ghana cocoa farms: further structural considerations. Journal of Applied Ecology:145-155.

Majer J. 1976b. The maintenance of the ant mosaic in Ghana cocoa farms. Journal of Applied Ecology:123-144.

Majer J, and Camer-Pesci P. 1991. Ant species in tropical Australian tree crops and native ecosystems-is there a mosaic? Biotropica:173-181.

Majer JD, Delabie JH, and Smith MR. 1994. Arboreal ant community patterns in Brazilian cocoa farms. Biotropica:73-83.

Parr CL. 2008. Dominant ants can control assemblage species richness in a South African savanna. 
384

385

386

Pfeiffer M. 2013. Antbase: a taxonomic ant picturebase of Asia and Europe www.antbase.net (accessed 10 May 2017).

Pfeiffer M, and Linsenmair KE. 2000. Contributions to the life history of the Malaysian giant ant Camponotus gigas (Hymenoptera, Formicidae). Insectes Sociaux 47:123-132.

Pfeiffer M, and Linsenmair KE. 2001. Territoriality in the Malaysian giant ant Camponotus gigas (Hymenoptera/Formicidae). Journal of Ethology 19:75-85.

Pfeiffer M, and Linsenmair KE. 2007. Trophobiosis in a tropical rainforest on Borneo: Giant ants Camponotus gigas (Hymenoptera: Formicidae) herd wax cicadas Bythopsyrna circulata (Auchenorrhyncha: Flatidae). Asian Myrmecology 1:105-119.

Pfeiffer M, Tuck HC, and Lay TC. 2008. Exploring arboreal ant community composition and co-occurrence patterns in plantations of oil palm Elaeis guineensis in Borneo and Peninsular Malaysia. Ecography 31:21-32.

Ribeiro SP, Espírito Santo NB, Delabie JHC, and Majer JD. 2013. Competition, resources and the ant (Hymenoptera: Formicidae) mosaic: A comparison of upper and lower canopy. Myrmecological News 18:113-120.

Rigato F. 1994. Revision of the myrmicine ant genus Lophomyrmex, with a review of its taxonomic position (Hymenoptera: Formicidae). Systematic Entomology 19:47-60.

Room PM. 1971. The relative distributions of ant species in Ghana's cocoa farms. The Journal of Animal Ecology 40:735-751.

Room PM. 1975. Diversity and organization of the ground foraging ant faunas of forest, grassland and tree crops in Papua New Guinea. Australian Journal of Zoology 23:71-89.

Schödl S. 1998. Taxonomic revision of Oriental Meranoplus F. Smith, 1853 (Insecta: Hymenoptera: Formicidae: Myrmicinae). Ann Naturhist Mus Wien Ser B Bot Zool 100:361-394.

Stone L, and Roberts A. 1990. The checkerboard score and species distributions. Oecologia 85:74-79.

Tanaka HO, Inui Y, and Itioka T. 2009. Anti-herbivore effects of an ant species, Crematogaster difformis, inhabiting myrmecophytic epiphytes in the canopy of a tropical lowland rainforest in Borneo. Ecological Research 24:1393-1397.

Tanaka HO, Yamane S, and Itioka T. 2010. Within-tree distribution of nest sites and foraging areas of ants on canopy trees in a tropical rainforest in Borneo. Population ecology 52:147-157. 
413 Tanner CJ, and Adler FR. 2009. To fight or not to fight: context-dependent interspecific aggression in $414 \quad$ competing ants. Animal Behaviour 77:297-305.

415 Way M, and Khoo K. 1991. Colony dispersion and nesting habits of the ants, Dolichoderus thoracicus and 416 Oecophylla smaragdina (Hymenoptera: Formicidae), in relation to their success as biological 417 control agents on cocoa. Bulletin of Entomological Research 81:341-350.

418 Yusah KM, Fayle TM, Harris G, and Foster WA. 2012. Optimising diversity assessment protocols for high $419 \quad$ canopy ants in tropical rain forest. Biotropica 44:73-81.

420 Yusah KM, and Foster WA. 2016. Tree size and habitat complexity affect ant communities (Hymenoptera: 421 Formicidae) in the high canopy of Bornean rain forest. Myrmecological News 23:15-23. 
Figures
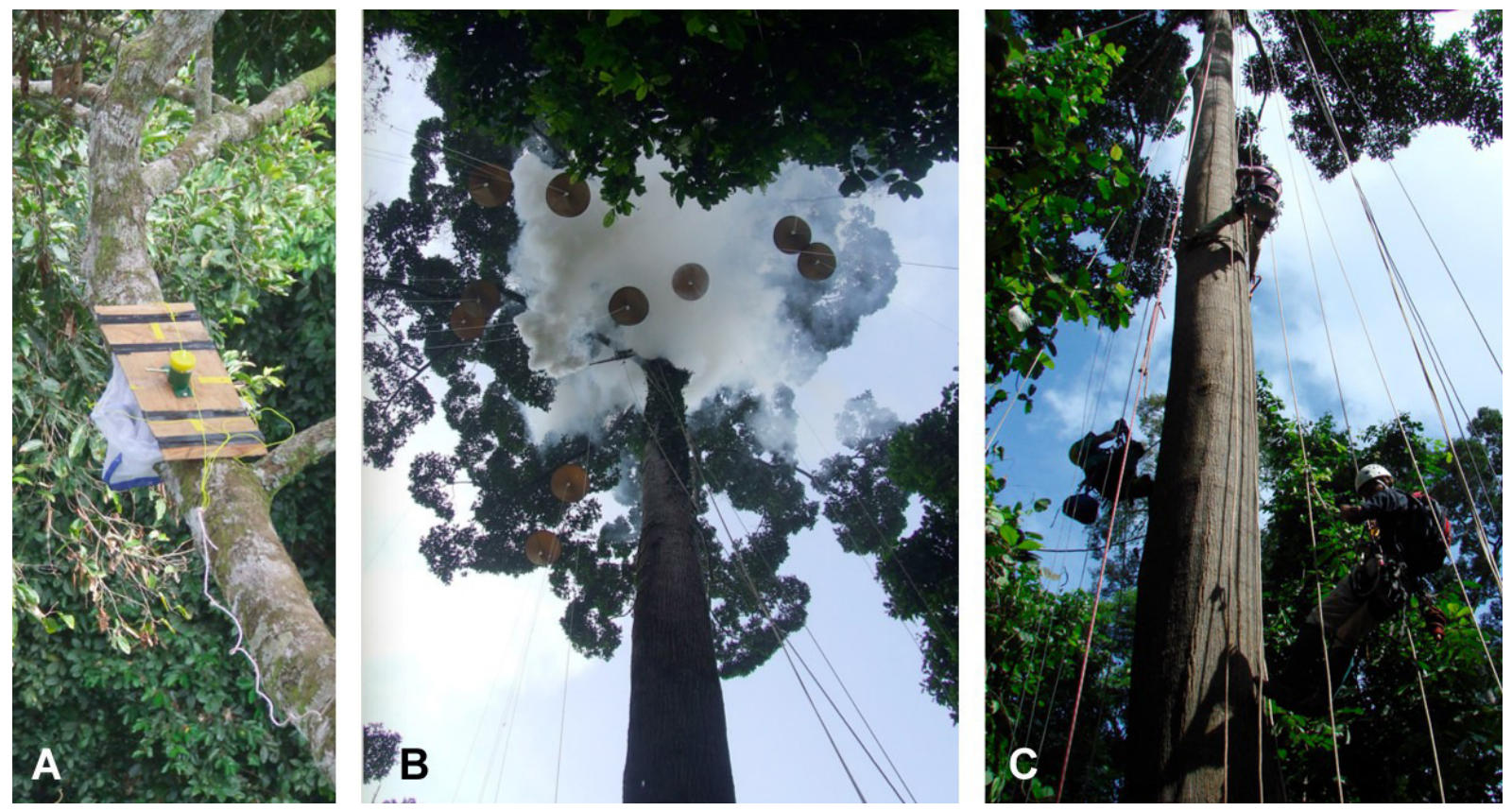

423 Figure 1. Ant communities were sampled using (A) bait-based purse-string trapping and (B) fogging with

424 fogging machine and trays hoisted into the canopy. Both methods exclusively sample ants in the crown of 425 the focal tree and were conducted using rope access (C). 

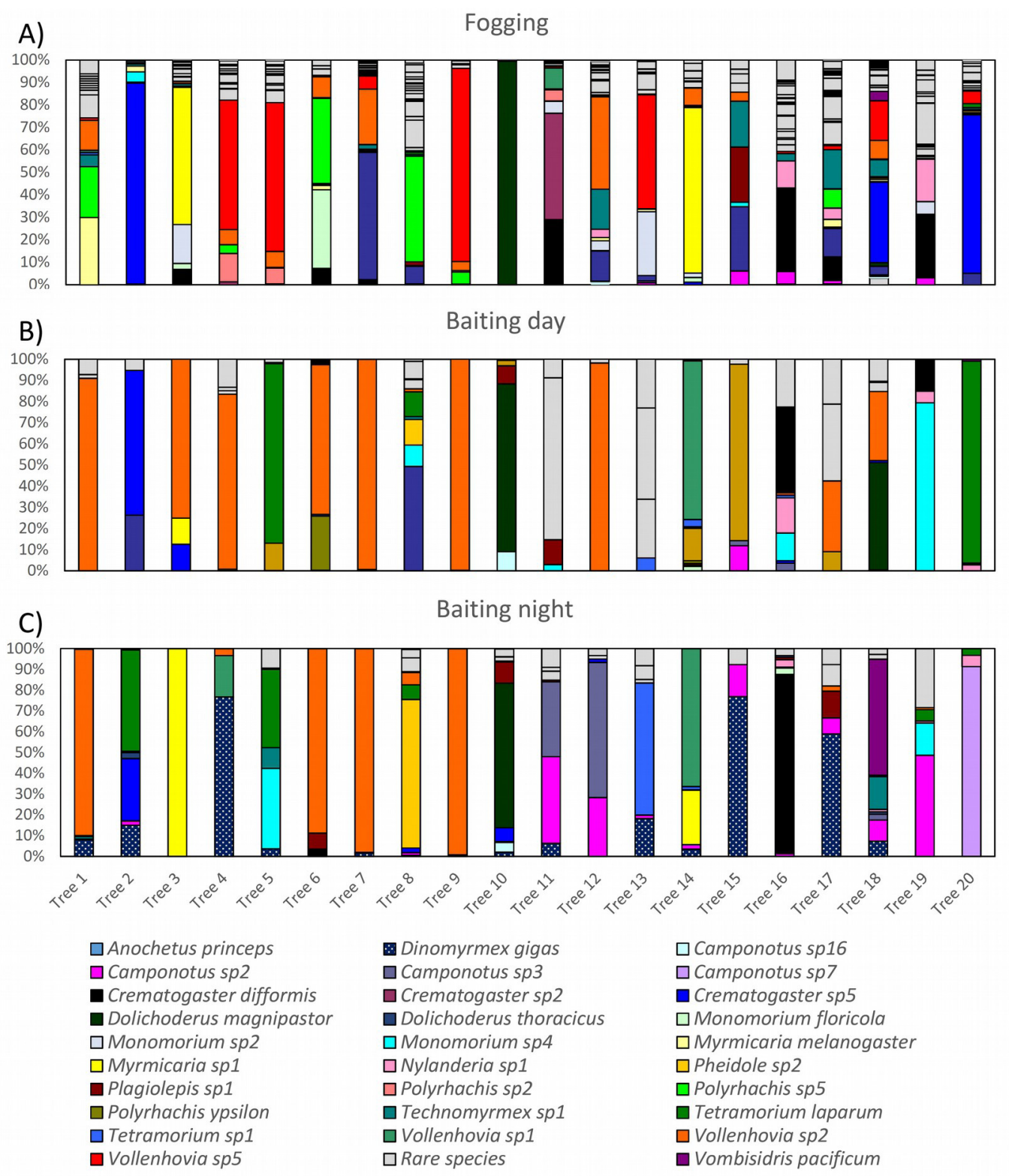

426 Figure 2. Ant communities were highly diverse, for both fogging (A) and baiting (B, $C)$. Different colours/patterns denote abundances of different ant species and each column shows the ant community

428 from a single tree, with numbering of trees and colouring of ant species being consistent between different

429 sampling methods and times of day. To avoid using many similar colours, we only coloured ant species

430 that were either the first or second most abundant species on a tree for a particular sampling method, and

431 were also found with an abundance of at least 50 on at least one tree. Species not meeting these criteria

432 are coloured light grey, but are still distinguished individually by black outlines. We also coloured two

433 large-bodied species that did not (quite) meet these criteria: Dinomyrmex gigas and Polyrhachis ypsilon. 

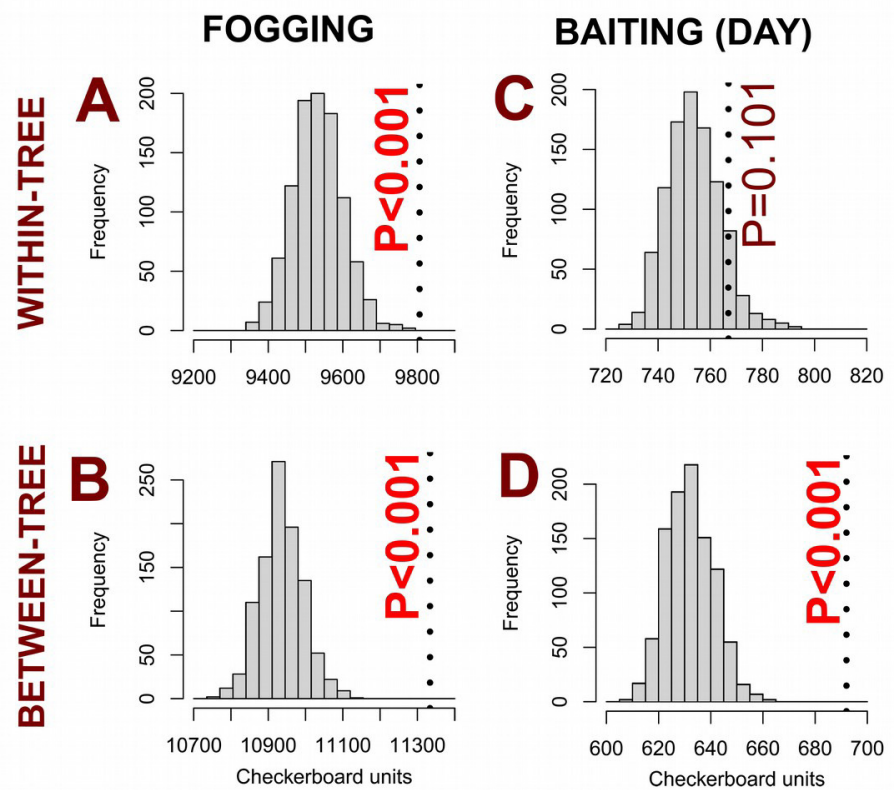
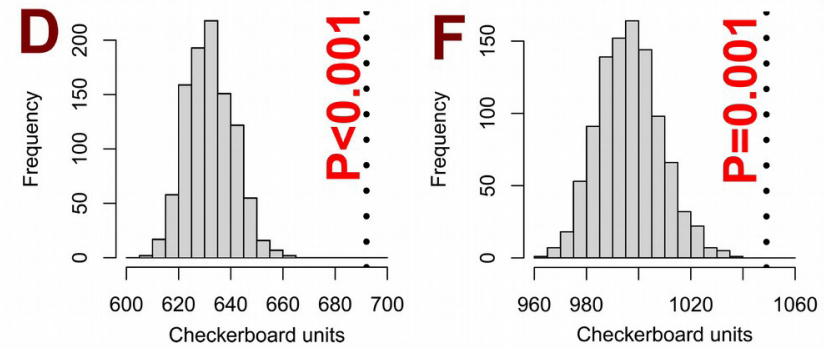

434 Figure 3. Ant communities were segregated for most combinations of scale and sampling: canopy-based 435 fogging $(A, B)$, baiting (day: $C, D$; night: $E, F$ ). Only baited ants at within-tree scales during the day were not segregated (C). Histograms show expected distribution of chequerboard units if species co-occur at random, while vertical broken lines denote observed number of species co-occurrences. Where the vertical line is to the right of the histogram, there are more chequerboard units than expected and hence there is segregation between species (P-values in bold red are statistically significant). Note that for the between-tree analysis the histograms represent the results of a single example selection of sampling units to create "trees", while p-values have been calculated using all ten tree selections. Hence, histograms (but not $p$-values) will show minor variations if code is rerun. 